\title{
Mathematical Language Skills of Mathematics Prospective Teachers
}

\author{
Nejla Gürefe \\ Department of Mathematics Education, Faculty of Education, Uşak University, Turkey
}

Copyright $(2018$ by authors, all rights reserved. Authors agree that this article remains permanently open access under the terms of the Creative Commons Attribution License 4.0 International License

\begin{abstract}
Effective mathematics teaching can be actualized only with correct use of the mathematical content language which comprises mathematical rules, concepts, symbols and terms. In this research, it was aimed to examine the mathematics prospective teachers' content language skills in some basic geometric concepts which are ray, angle, polygon, Pythagorean Theorem, area formula of trapezoid and surface area formula of the cone. Participants of the present study were constituted of third grade students in university. From results, it was determined that participants were not able to use the mathematical language adequately and usually not able to explain the concepts using symbols. It was also determined that there were some mistakes on the verbal level that the prospective teachers used to explain the concepts in the research.
\end{abstract}

Keywords Content Language, Geometry Education, Prospective Teacher

\section{Introduction}

Mathematics is a universal language [1] that ensures mutual communication between individuals through concepts, terms, symbols and grammar [2], which is referred as mathematical language. The language of mathematics is an important individual skill to allow understanding mathematical structures [3]. Achieving an effective teaching of mathematics is only possible by using the language of the field of mathematics that ensures the accurate transmission of mathematics [4]. The effective and accurate use of language is also highly important for individuals to explain what they understand and perceive, to develop the mutual communication between the student and teacher and to comprehend mathematical expressions. According [5], students can only establish an effective communication when they are able to speak in mathematics language. As most of the terms, symbols and concepts of mathematics are inexistent or rarely seen in everyday life, students are often unfamiliar to mathematics. If the teacher fails to use accurate concepts and terms when teaching to students the content of a lesson, students may perceive it in a different way or even attribute an incorrect meaning [6]. Hence the importance of students attributes the same meaning to mathematical expressions explained by the teacher. Misusing the language of the mathematical field will entail a poor communication between the student and the teacher, leading students, in the longer term, to conceptual errors for not being able to properly structure concepts in their minds. This is why math lessons require that language is used in accordance with mathematical knowledge. The examination of studies on mathematical language reveals that students have problems in using mathematical language accurately when conveying mathematical knowledge [7, 8]. Researches show that students can generally use symbols but without knowing their meaning [9].

Literature stresses that teachers play a very important role in the development of mathematical language $[10,11$, 12] and should guide students in their own use of that language. According to [11] students would not be able to use mathematical language without assistance. [12] also argues that students can learn the rules of mathematical language through teachers' explanations. Considering the development of students' mathematical communication skills and ability to use mathematical language correctly, the accurate and effective use of mathematical by teachers in classrooms gains importance. [13] has also affirmed that math teachers should be competent in using mathematical language and forms of mathematical representation.

Literature includes studies on the impact of mathematical language used by students on their understanding of mathematical concepts and terms in math lessons [14], the definition of understanding mathematical texts [15], identification of students' skill levels in using mathematical language [16, 17], mathematical skills of math prospective teachers $[18,19]$, thoughts of math prospective teachers on language in education of mathematics [6], and mathematical language skills regarding patterns $[16,20]$. No study was found explaining how prospective teachers made use of mathematical 
language, including basic concepts of geometry such as ray, angle or polygon and formulas such as the Pythagorean Theorem or the surface area of polygons and other geometrical forms. In this respect, this study is expected to add a contribution to the field. Especially geometry is one of the fields in math education where students often have difficulties and face problems in learning [21, 22, 23]. Because, geometry involves abstraction, symbols, terminology and solving problems [24]. The goal of math education is to develop students' problem-solving and reasoning abilities, improve their capacity to transfer knowledge and ensure they can correctly use mathematical language [25]. Considering that teachers play an important role in developing those skills, it is important to identify math prospective teachers' - who are the teachers of the future - own skills in using the field language of certain areas of geometry. This study reveals the knowledge by math prospective teachers of the field language in a number of geometry subjects.

\section{Methods}

This study is based on descriptive analysis, which is a qualitative research methodology. [26] has defined qualitative research methodology as a research based on a process allowing to show perceptions and events in their natural environment in a realistic and holistic way. In this study, we have chosen to adopt a qualitative research methodology to elucidate the research problem as it is a methodology used in order to obtain detailed explanations from natural environments. Research participants are 42 prospective teachers studying the third year of primary school math teaching at a university in Western Turkey. Research participants were asked a total of six open questions, three of which requiring the correct use of the conceptual knowledge and mathematical terminology related to some basic concepts of geometry (ray, angle, polygon) and three others involving to express rules and principles defined by symbols (hypotenuse relationship, surface area formula for trapezoids and the surface area of a cone) using a correct content and mathematical language. Questions were prepared upon consultation with two math teachers, both with expertise in their fields, and three questions out of the initial nine were considered too detailed and dismissed after their expert opinion was sought. The question sheets with open questions were distributed to prospective teachers, who were asked to answer them in writing. Data obtained in this study were assessed based on content analysis methodology. During the analysis, data were treated in two different ways, one focusing on the use of symbols and the other on explanations made by participants. Symbols and explanations were classified under categories "correct", "partially correct", "incorrect" and "empty". Multiple educational resources such as textbooks and math dictionary was examined to decide which the definition was used as correct definitions and decided to use definitions based on the definitions included in the book Tags of Basic Mathematical Concepts by [27] detect the accuracy of explanations using symbols. Symbols and explanations used in accordance with these definitions were considered as correct, symbols and explanations with critical characteristics properly defined although used incorrectly were considered as partially correct, symbols used inaccurately due to the lack of mathematical knowledge and explanations with inadequate use of mathematical terminology or including elements from everyday language as well as parts containing mistakes were considered as incorrect.

\section{Findings}

Findings obtained from the study have been treated under six headings, i.e. ray, angle, polygon, Pythagorean Theorem, surface area formula for trapezoids and surface area formula for cones. The symbols and explanations related to ray, angle and polygon and the frequencies were listed in Table 1.

Table 1. Explanation type frequency by symbol and explanation accuracy

\begin{tabular}{|c|c|c|c|c|c|c|c|c|c|c|c|c|}
\hline \multirow{2}{*}{ Symbol } & \multicolumn{3}{|c|}{ Correct explanations } & \multicolumn{3}{|c|}{ Partially correct explanations } & \multicolumn{3}{|c|}{ Incorrect explanations } & \multicolumn{3}{|c|}{ Empty } \\
\hline & $\mathrm{R}$ & A & $\mathrm{P}$ & $\mathrm{R}$ & A & $\mathrm{P}$ & $\mathrm{R}$ & A & $\mathrm{P}$ & $\mathrm{R}$ & $\mathrm{A}$ & $\mathrm{P}$ \\
\hline Correct & 0 & 1 & 0 & 0 & 0 & 0 & 0 & 0 & 0 & 0 & 1 & 0 \\
\hline $\begin{array}{c}\text { Partially } \\
\text { correct }\end{array}$ & 0 & 0 & 0 & 0 & 0 & 0 & 0 & 0 & 0 & 0 & 0 & 1 \\
\hline Incorrect & 10 & 1 & 1 & 0 & 0 & 11 & 20 & 29 & 12 & 12 & 10 & 17 \\
\hline Empty & 0 & 0 & 0 & 0 & 0 & 0 & 0 & 0 & 0 & 0 & 0 & 0 \\
\hline
\end{tabular}

Note. Using symbols and explanations are bolded. R: Ray, A: Angle, P: Polygon 


\subsection{Findings Regarding Concept of Ray}

Prospective teachers were asked to "Can you explain the concept of ray using mathematical symbols?" As shown in Table 1, none of the prospective teachers were able to provide an explanation using the correct symbols to the question requiring explaining the concept of ray with symbols. Ray is a line segment $[A B]$ and the connection

of a set of $X$ points that are not on the line segment and is coded as $[A B$. In other words, a ray is the following:

$$
\begin{aligned}
& {[A B=[A B] \cup\{X:|A B|+|B X|=|A X|\}} \\
& \overrightarrow{\mathrm{B}} \quad \overrightarrow{\mathrm{X}}
\end{aligned}
$$

[27]. While participants were expected to use a symbol expressing the connection of a line segment and a $x$ point, none employed such symbol. Students identified ray with the symbols " $A B,[A B), A B,[A B[] A B$,$] "or showed$ it on the shapes (Figure 1), saying the symbol of the ray were these signs. What they wrote demonstrates that most of the participants showed the symbol of ray accurately. However, explanations they made such as "this is the symbol of ray" revealed that they erroneously perceived explaining a concept with symbols as the symbol of the concept itself. Even here some of the prospective teachers showed the symbol of ray inaccurately ("[AB[","]AB]") .

Students' responses falling in the category of incorrect use of symbol but correct explanation were " $a$ set of points extending indefinitely in one direction from a defined starting point" and "a set of points extending indefinitely in one direction with the other closed". Considering the definition of a ray, it involved a line segment and an $x$ point not situated on the line segment itself but connected with it. In other words, the ray could be explained as the connection of a set of points extending indefinitely with a definite starting point. Therefore, above mentioned student's responses said that a ray is the connection of a set of points with a definite starting point but indefinite end can be considered as correct. Some participants made the following explanations for a ray, which were considered as incorrect: "a line segment with a closed end (full) and the other end and an ongoing end", "a line with a closed end and an open end".

A ray is not a line or a line segment. Students used here an inaccurate mathematical terminology. Twelve participants used incorrect symbols without providing any explanation.

When analyzing student answers, although 10 participants were able to provide a correct explanation, a large majority $(\mathrm{n}=20)$ explained it incorrectly or were unable to provide any explanation $(n=12)$. All of the participants who were unable to provide explanations only contented to show a ray with symbols. Most of the participants explained the ray with the terms "line, set of points, line segment, two-poled thing and X-axis" (Table 2).

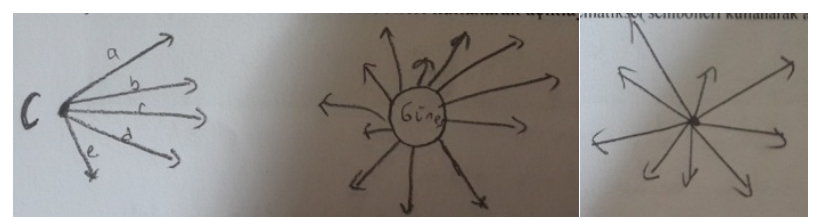

Figure 1. Shapes Drawn by the Participants for Ray

As shown in the Figure 1, participants likened the ray to sunlight. They considered the sun as the starting point and drew the lights as extending indefinitely.

When it was considered Table 2, it was seen that a large majority of participants thought of the ray as a form with two definite with a starting and ending point and generally explained as having a defined starting point and a second end indefinitely extending to infinity. It could be said that answers of participants explaining a ray as a line or a line segment were inconsistent. Students who said that a ray is a line or line segment which has one closed end and another indefinite had inconsistent answers. Because, they were either limiting one end of a line by saying it is closed/limited or failing to limit the line segment by saying that one of it ends is indefinite. In fact, both ends of a line are indefinite while both ends of a line segment are definite.

\subsection{Findings and Comments Regarding the Concept of Angle}

As shown in Table 3, a large majority of participants $(n=29)$ did incorrect explanation to the question requiring explaining the concept of angle by using incorrect symbols. Only one student who provided a correct explanation using correct symbols defined angle as "the connection of two rays with the same starting point [BA $U$ $[C A$ ". Another one student used the symbol accurately but drew a shape instead of providing an explanation. His answer was as follows: $<[A B U[B C$ ”. Except these two answers, the use of symbols was incorrect in all the other answers while one participant provided a correct explanation: "rays with the same starting point form an angle or an angle can be formed if the starting points of rays are superposed". Others $(\mathrm{n}=29)$ were incorrect explanations, which included "the distance between two lines with adjacent starting points", "the measure between two line segments", "a distance formed between the intersection of two lines" and "the arc measure formed and remaining in between two line segments is called angle". Ten participants used an incorrect symbol without providing any explanation. The participants who explained angle with a symbol made use of the symbolic indication, i.e. $A \hat{B} C=\alpha$ and the pictorial representation on Figure 2. An angle is in fact the connection set of two rays with the same starting point, represented as $\left[A B \cup\left[A C=(B \hat{A A C})=\hat{A}^{\text {[27]. Therefore, participants were }}\right.\right.$ expected to use symbols that would express the set of connection of rays when explaining angles with symbols. All participants, except two, perceived the task of 
explaining angle with symbols as writing down the symbol of the angle, using symbols that represented the degree of the angle instead of angle itself.

A majority of participants $(n=38$, more than one category or subcategory sometimes was identified in each answer, the total number of frequencies was greater than the number of participants in Table 1) provided explanations in addition to using symbols. Students explained angle with the following words: "distance/openness, measure, shape, geometric region and numerical value" (Table 3 ).

According to the data shown in Table 3, participants mostly defined angle as a "distance/openness" $(\mathrm{n}=18)$, measure $(\mathrm{n}=8)$ and shape $(\mathrm{n}=8)$, region $(\mathrm{n}=2)$ and numerical value $(\mathrm{n}=2)$. Unfortunately, the participants who explained angle as a distance, measure and numerical value between rays, lines, line segments, sides, arcs and vectors expressed angle as the degree of the angle. It is clear that participants who explained angle as the connection of rays with the same starting point or the connection of lines extending from the same point were able to distinguish angle from degree of angle. While participants who expressed that an angle was the connection of two rays with the same starting point provided a correct explanation, only one of those participants was able to express it properly using symbols. Furthermore, participants who defined angle as the area formed by the intersection of two lines were in fact describing the interior area of the angle. However, the student did not explain how the lines intersected (a sole point or superposed). The student who explained angle as a proportion referred to the arc and perimeter at the circumference.

\subsection{Findings and Comments Regarding the Concept of Polygon}

As shown in Table 4, only one of the participants was able to write the symbol partially correct but without providing any explanation and only one participant wrote incorrect symbol, but made correct explanation. The majority of the participants $(n=40)$ provided explanations but used the symbol incorrectly to answer the question which required to explain the concept of polygon using symbols. Among the participants who used an incorrect symbol, only one provided a correct explanation, 11 participants provided a partially correct explanation, 12 participants made incorrect explanation whereas 17 participants did not provide any explanation at all. A polygon is defined as the set consisting of three, as a natural number non-linear $\mathrm{A} 1, \mathrm{~A} 2, \ldots, \mathrm{An}$ points in the same plane [27].

Table 2. Explanations provided for the concept of ray

\begin{tabular}{|c|c|c|c|}
\hline Geometric shapes & Categorizes & Sub-categorizes & f \\
\hline \multirow{8}{*}{ Line } & \multirow{5}{*}{ two-poled } & the beginning is definite, the end is infinite & 6 \\
\hline & & the beginning is definite, the end is not. & 1 \\
\hline & & one is closed, the other is infinite & 1 \\
\hline & & one pole is limited & 1 \\
\hline & & one is closed, the other is open & 1 \\
\hline & has beginning & beginning is a point & 2 \\
\hline & directional & goes infinite & 1 \\
\hline & Total & & 13 \\
\hline \multirow{5}{*}{ Set of points } & moving & goes infinite from one point which is empty or full & 5 \\
\hline & \multirow{3}{*}{ two-poled } & one is limited / fixed, the other is infinite & 1 \\
\hline & & one is closed, the other is infinite & 1 \\
\hline & & the beginning is definite, and goes infinite & 1 \\
\hline & Total & & 8 \\
\hline \multirow{5}{*}{ Line segment } & \multirow{4}{*}{ two-poled } & one is closed (full), the other goes & 1 \\
\hline & & \multirow{2}{*}{$\begin{array}{l}\text { one is fixed, the other is infinite } \\
\text { one is the finite, the other is infinite }\end{array}$} & 1 \\
\hline & & & 1 \\
\hline & & thousands line segment which come from one point & 1 \\
\hline & Total & & 4 \\
\hline Two-poled thing & closed and infinite & One is closed, the other is infinite & 3 \\
\hline $\mathrm{X}$-axis & positive & its beginning is the origin) & 2 \\
\hline
\end{tabular}




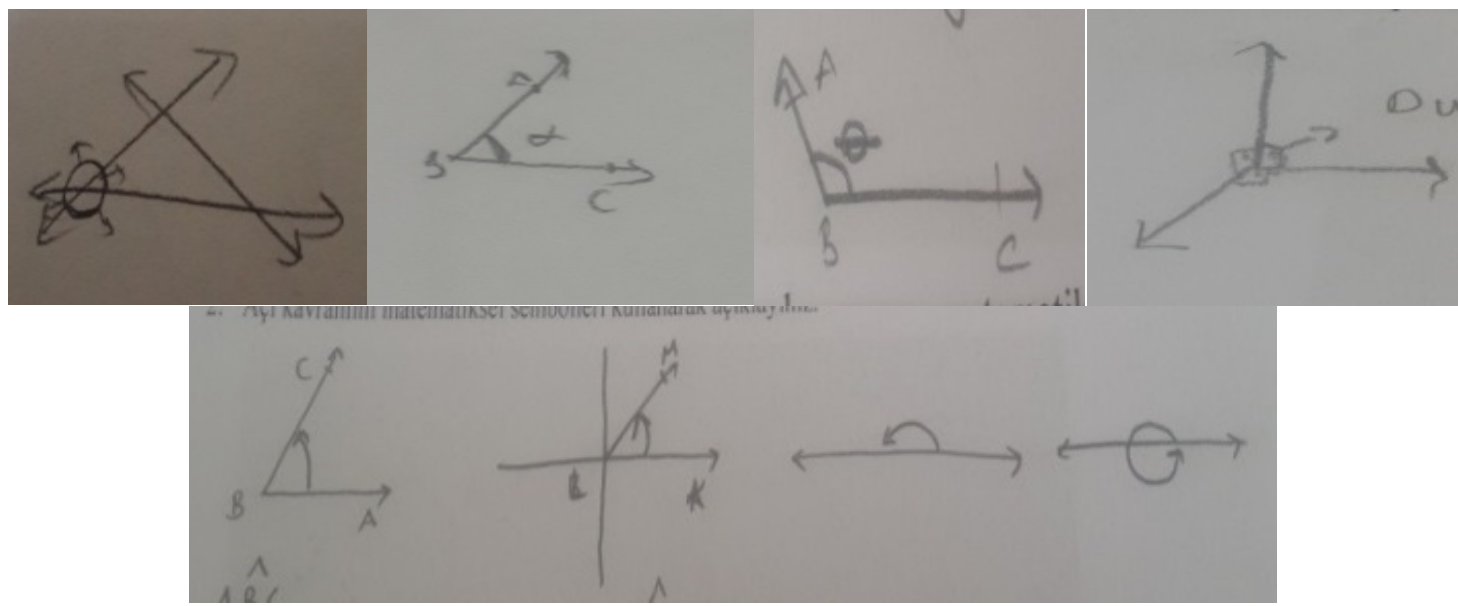

Figure 2. Angle Symbols of Participants

Table 3. Explanations provided for the concept of angle

\begin{tabular}{|c|c|c|c|}
\hline Geometric shapes & Categories & Sub-categories & f \\
\hline \multirow{7}{*}{ Distance/ openness } & \multirow{2}{*}{ between rays } & any two rays & 5 \\
\hline & & two rays whose beginning points are the same & 5 \\
\hline & \multirow{2}{*}{ between lines } & two lines & 3 \\
\hline & & two lines whose beginning points are the same & 2 \\
\hline & between line segments & two line segments & 2 \\
\hline & between edges & beginning edge and end edge & 1 \\
\hline & Total & & 18 \\
\hline \multirow{7}{*}{ Measure } & \multirow{2}{*}{$\operatorname{arc}$} & occurs the intersection of two rays & 1 \\
\hline & & occurs the intersection of at least two lines & 1 \\
\hline & between lines & occurs the intersection of two lines & 2 \\
\hline & between rays & any two rays & 2 \\
\hline & between edges & two edges & 1 \\
\hline & between line segments & any two line segments & 1 \\
\hline & Total & & 8 \\
\hline \multirow{4}{*}{ Shape } & combination of rays & two rays whose beginning points are the same & 6 \\
\hline & combination of lines & two lines which come from same points & 1 \\
\hline & combination of surfaces & two surface which intersect each other & 1 \\
\hline & Total & & 8 \\
\hline Region & being composed by lines & two lines which intersect each other & 2 \\
\hline \multirow{3}{*}{ Numerical value } & between lines & lines which intersect each other & 1 \\
\hline & Between vectors & extent in positive direction between two vectors & 1 \\
\hline & Total & & 2 \\
\hline
\end{tabular}

According to this definition, any set of connection of line segments formed by the connection of non-linear points in twos creates a polygon. Students who provided this explanation using the symbols expressed in the definition were considered under the category of correct use of symbol and correct explanation. No student was able to both use a correct symbol and provide a correct explanation. However, one student explained the polygon with the expressions provided in Figure 3.

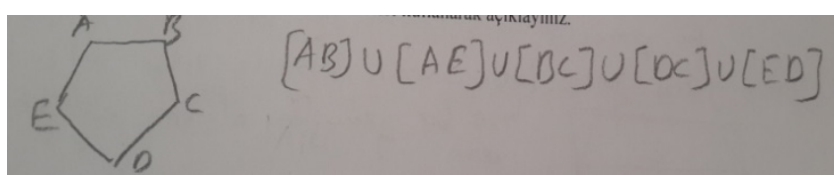

Figure 3. Symbol (Partially correct-explanation empty)
The explanation provided in Figure 3 by the student whose use of symbol is partially correct shows that the student specified polygon as a pentagon, without generalizing that a polygon could be have an $n$ number of edges. The student identified the line segments representing the edges of the polygon, describing them as line segments and explained the pentagon by randomly connecting those line segments. The student was unable to consider that points forming line segments in a polygon should be connected in twos one after another until the last point is connected to the starting point in order to create a closed shape. Still, the student's explanation according to which a polygon is the connection of line segments provides some of the critical characteristics $([A B] \cup[A E] \cup[B C] \cup[D C] \cup[E D])$ in the definition of a 
polygon. Therefore, the answer of the student was placed under the category of partially correct use of symbols. The answer of the student who used an incorrect symbol but provided a correct explanation was " $a$ a polygon] is the closed shape connecting in twos an n number of points such as $A_{1}, A_{2}, A_{3}$, none of which being linear". The student indicated that any of the three points of a polygon should not be linear, that points would be connected in twos eventually leading to a closed form. Some of the answers of participants who used an incorrect symbol and provided a partially correct explanation are: " $A$ shape/closed shape formed by the connection of at least three line segments", "a shape with at least three edges".

Each student answer contains some of the critical characteristics of a polygon such as being formed of at least three line segments and being a closed-shape, having at least three edges. As a result, these explanations were placed under the category of partially correct. Student answers with both an incorrect use of symbol and explanation include the following: "a closed curve with 3 or more than 3 edges", "formed by the connection of line segments with $n$ edges". These consisted of terminology which is not characteristic of a polygon, such as closed curve and line segments with edges. These types of explanations were considered under the incorrect category. Some of the participants used symbols such as $A \stackrel{B}{B C}$ and $A B C D$ and almost all of the participants drew figures shown in Figure 4 or similar figures. These show that participants understood from explaining a concept using symbols to draw the shape of what they thought the concept meant or to use the symbol representing the concept.

Table 4. Explanations provided for the concept of polygon

\begin{tabular}{|c|c|c|c|}
\hline Polygon & Category & Sub Category & f \\
\hline \multirow{11}{*}{ Geometric shape } & with sides & Three or more than three edges & 4 \\
\hline & connection of lines & formed by the connection of at least three lines & 1 \\
\hline & intersection of lines & at least three lines & 1 \\
\hline & \multirow{4}{*}{ connection of line segments } & formed by the connection of the ends of line segments & 1 \\
\hline & & $\begin{array}{l}\text { formed by the connection of the starting and ending points of line } \\
\text { segments one after another }\end{array}$ & 1 \\
\hline & & at least three line segments & 1 \\
\hline & & line segments with $n$ edges & 1 \\
\hline & connection of segments & at least three segments & 1 \\
\hline & with corners & having three or more than three corners (provided they are non-linear) & 1 \\
\hline & angle and edges & angles and edges are unequal & 1 \\
\hline & Total & & 13 \\
\hline \multirow{6}{*}{ Closed shape } & connection of points & $\begin{array}{l}\text { connection in twos of } \mathrm{n} \text { points such as } \mathrm{A}_{1}, \mathrm{~A}_{2}, \mathrm{~A}_{3} \text {, none of the three } \\
\text { linear }\end{array}$ & 1 \\
\hline & connection of line ends & connection of many line ends with at least three edges & 1 \\
\hline & with angle and corner & three successive corners not situated on a line & 1 \\
\hline & \multirow{2}{*}{ connection of line segments } & connection of at least three line segments & 1 \\
\hline & & formed by the connection of $n$ line segments & 1 \\
\hline & Total & & 5 \\
\hline \multirow{3}{*}{$\begin{array}{l}\text { Connection of } \\
\text { geometric forms }\end{array}$} & connection of edges & connection of different edges linked one to another & 1 \\
\hline & connection of line segments & connection in twos of the ends of line segments with different lengths & 1 \\
\hline & Total & & 2 \\
\hline $\begin{array}{l}\text { Figure with } \\
\text { region }\end{array}$ & intersection of line segments & at least three line segments & 1 \\
\hline Closed plane & formed by edges & formed by more than three edges & 1 \\
\hline Closed curve & having edges & more than 2 edges & 1 \\
\hline $\begin{array}{c}\text { Geometric } \\
\text { object }\end{array}$ & connection of lines & at least three lines & 1 \\
\hline
\end{tabular}

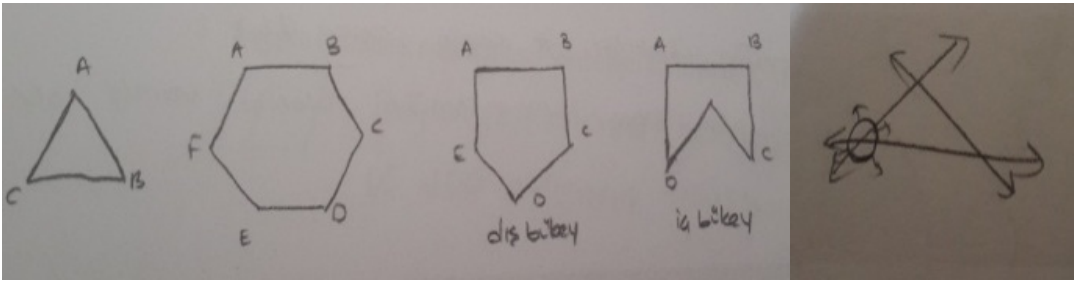



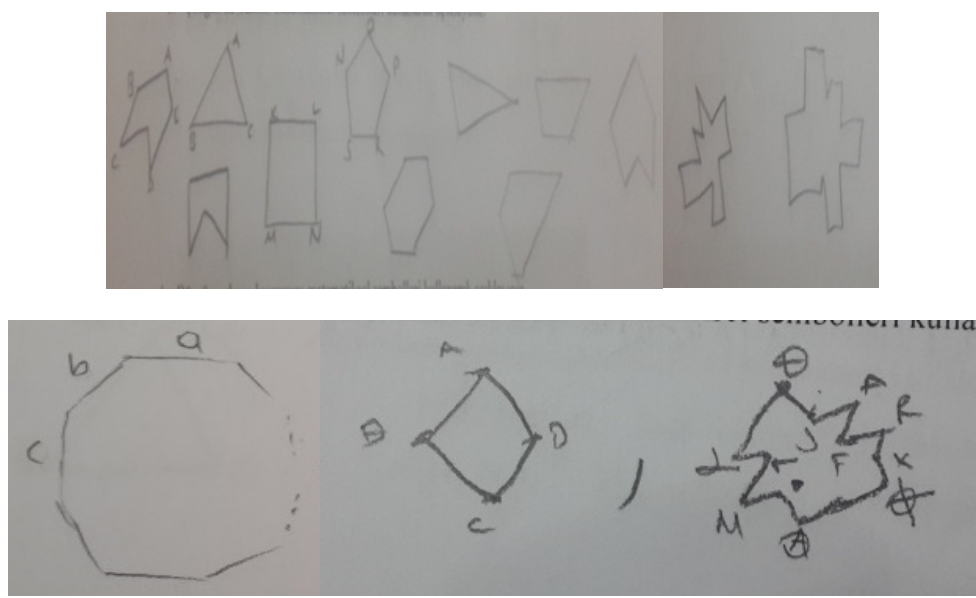

Figure 4. Polygon Shapes Drawn by the Participants

Table 5. Adequacy of Verbal Expression Related to Rules

\begin{tabular}{|c|c|c|c|c|}
\hline & Correct & Partially correct explanations & Incorrect explanations & Empty \\
\hline Pythagorean & 9 & 17 & 15 & 1 \\
\hline Area formula of trapezoid & 8 & 17 & 17 & 0 \\
\hline Surface area formula of cone & 6 & 14 & 12 & 10 \\
\hline Total & $\mathbf{2 3}$ & $\mathbf{4 8}$ & $\mathbf{4 4}$ & $\mathbf{1 1}$ \\
\hline
\end{tabular}

Twenty-four participants provided explanations about polygons. Explanations regarding polygons show that participants perceived the polygon as a geometric shape, closed-shape, and connection of geometric shapes, the shapes with region, a closed plane, a closed curve and a geometrical object.

Looking through the data shown in Table 4, we can see that students mostly explained a polygon according to the number of edges or line segments, while only a few defined it based on the corner points being mindful that any three points must not be linear. If the participants had defined the polygon according to the corner points, they might have been able to refer to the linearity of the points as students who provided a definition based on the corner have all stressed the linearity. Some participants have said the connection of lines or lines' ends made up the polygons. However, looking at the shapes drawn by those participants regarding this explanation, we can see that they described polygon the closed figure formed by the connection of lines in twos or the figure they formed by connecting the ends of rays. It can be said that the shapes drawn by participants and their explanations are inconsistent. Furthermore, a participant explained a geometric shape with unequal angle and edges as a polygon. This entailed that the participants were not aware that polygons are divided into regular and irregular polygons or proposed an explanation without being mindful of this fact. One of the participants said a polygon is the geometric figure formed by the connection of $n$ edged line segments, which showed that he considered a line segment as a figure with edges.

\subsection{Findings Related to Explaining Rules Verbally}

Findings related to the Pythagorean Theorem, the patch size of the patch, and the shapes of the surface area measure of the prospective teachers were explained in Table 5 by verbal language.

\subsubsection{Finding Regarding the Pythagorean Theorem}

The analyses of the data in Table 5 show that nine participants were able to explain the Pythagorean Theorem with correct verbal answers. Some of the answers in this category include: "In a right-angled triangle, the square of the length of the hypotenuse equals the sum of the squares of the other edges", "The sum of the squares of the legs equal the square of the hypotenuse's length". As the oral definition explaining Pythagorean Theorem is "In a right-angled triangle, the square of the length of the hypotenuse equals the sum of the square of the length of the legs", answers given by nine participants were considered as correct. Other 17 participants have partially correctly answered this theorem with explanations such as "In a right-angled triangle, the hypotenuse equals the square root of the sum of the squares of the legs". Meanwhile, 15 participants provided incorrect answers, including "In a right-angled triangle, it allows to find the length of the hypotenuse", "the length of the hypotenuse is $b^{2}=a^{2}+c^{2}-2 a b \cos 90, b^{2}=a^{2}+c^{2}$ ", "The sum of the adjacent edges next to the right angle provide the square of the edge that ensures the connection of adjacent edges with each other", $"|A B|^{2}+|B C|^{2}=|A C|^{2} "$. One student did not provide any explanation at all. Students who provided a partially correct answers were referring to the sum of the square of 
edges, however they failed to notice that what was being summed was the squares of the lengths of the edges, which is why their answers were considered only partially corrects. Incorrect answers were either made with the use of symbols while an oral explanation was expected from them or provided oral explanations that were far from using terminologies that would clarify the theorem.

\subsubsection{Surface Area Formula for Trapezoids}

The analysis of the data in Table 5 show that only eight participants were able to explain the surface area formula as verbal for trapezoids correctly. The answers falling in this category include: "In a trapezoid, the multiplication of the sum of the edges and the height of the trapezoid divided in two equals the surface. The lower base represented by $a$, the upper base by $c$ and the height by h". Seventeen participants provided partially correct answers such as: "The surface of the trapezoid is found by the sum of the lower and upper bases. It is multiplied by the height then divided by two", "It is found by the sum of the lengths of the two parallel edges of the trapezoid multiplied by the length between the two parallel edges and the result divided in two". Other 17 participants gave incorrect explanations that included the following: "The height of the AH trapezoid is at the same time the height of the AHD triangle. [Surface area] in a triangle is found by the multiplication of the base by the height divided by two. From here the surface area of the trapezoid is found by the multiplication of bases by the height divided in two", "The surface equals the multiplication of an edge by the height of the base. Here two triangles formed with the [AC] diagonal give us the surface area", "The surface area of the trapezoid equals half of the multiplication of the sum of the short and long bases by the height", "It equals half of the multiplication of the sum of parallel lines by the height". Responses of participants falling in the partially correct category referred to the sum of the lower and upper bases, however what is summed are not the bases themselves but their lengths. Furthermore, the expression "... the lengths between two parallel edges ..." was aiming to describe the length between parallel edges and the height, however the concept of verticality was not stressed for expressing the length. As the answer was not mindful of the bases' length and the vertical length regarding the height, these answers were considered only as partially correct. Answers falling in the incorrect category were generally using oral explanations lacking expressions that would help to clarify the theorem.

\subsubsection{Surface Area of the Cone}

Findings in Table 5 show that only six participants were able to explain the surface area formula of the cone by using proper terminologies verbally. Correct student answers are as follows: "To find the surface area of a cone, we calculate the surface areas of shapes one by one and add them. Firstly, the surface of the base is the multiplication of the square of the circle's radius by $\pi$. Then, the area of the shape forming the lateral side of the cone is proportional to the angle. The square of the length of the lateral edge is found by the multiplication of that angle by $\pi$, the result being divided by 360". Fourteen participants have provided partially correct answers for this theorem, that include: "The surface area of the cone is the sum of the surface area of the circle and the surface area of the circle sector", "It is found by the sum of the base surface area, meaning the surface area of the circle and the formula of the shape above", "When opening a cone, we obtain a circle and a circle sector. Their surface areas give us the cone's surface area". Other 12 participants provided incorrect answers, among which: "We add the surface area of the triangle with a sector", "It is found by the surface area of the circle formed in the base of the cone multiplied by the square of the arc facing the base, i.e. the edge of the cone", "The base being a ring the surface area of the cone is obtained by the sum of the surface area of the ring and the square of the radius", "It is found by the sum of the surface area of the base with the length of the arc of the angle". "Since its surface area is a ring, the surface area of the cone is obtained by the sum of the surface area of the ring and the square of the radius", "It is found by the sum of the surface area of the base with the length of the arc of the angle". Meanwhile 10 participants were unable to provide any answer at all. The formula provided in student answers falling in the category partially correct referred to the base and the lateral surfaces but did not explain how to calculate them. Therefore, these answers were only considered as partially correct. Incorrect answers consisted of inaccurate explanations expressing the base of the cone as a ring, considering the lateral surface as a triangle and addressing the surface of that form, arguing that the length of the lateral arc should be measured or saying that the cone had an edge.

\section{Results and Discussion}

The study expected from prospective teachers to explain some mathematical concepts by using symbols as well as orally explaining formulas provided with their rules resorting to mathematical terminology. The study intended to determine the sufficiency by prospective teachers of using the mathematical language and the way they made use of it. It eventually demonstrated that prospective teachers did not have enough sufficiency of using the language of mathematics. These findings are also supportive of a number of other works in filed literature [7, $8,18]$.

One of the findings stemming from the study is that prospective teachers had worse results in explaining concepts using symbols than using oral language. Some field literature researches also show similar results [16]. On the contrary, [28] found in a research conducted with 
secondary school students that a large majority of students were able to correctly explain quadrilateral shapes using either symbols or oral definitions. However, [28] has also demonstrated in a way that supports the findings obtained in our research that students were unable to explain the hierarchic relations between quadrilateral shapes using symbols while they were able to explain them by using oral definitions. In our study, none of the prospective teachers were able to explain a ray and a polygon by using symbols correctly and only one student could explain an angle. What most of the prospective teachers participating to the study understood from explaining a ray and angle was to provide the symbol of the ray or the angle. In other words, participants confused explaining a concept by using symbols with the symbol of the particular concept. Regarding the polygon, participants generally explained by drawing a shape which showed that prospective teachers perceived drawing as a symbolic explanation. Furthermore, in order to answer the question requiring them to provide an explanation using symbols only, not only did prospective teachers directly write down the symbols of the concepts or drew their shapes, but also they explained by using oral language. However, the analyses of those explanations show that the proportion of participants who provided an incorrect explanation is higher than those whose answers were correct. This demonstrated that prospective teachers did not accurately use mathematical terminology and would rather explain a mathematical expression with everyday terminology. Similar results were also obtained in the researches of $[18$, 29]. This may be the result of the avoidance by teachers or students to use the language of mathematics when defining concepts. When addressing a ray, prospective teachers have generally talked about something with two ends, explaining that this double-ended structure was a line or a line segment using expressions such as "a line with a closed and an open end", "a line segment with a closed (full) end and an ongoing end", "a line segment with two ends, one definite and the other indefinite". In fact, a ray is not a line segment with a definite and an indefinite end. The concepts of a ray, a line and a line segment are even different from each other. To such extent, a line segment is limited in both ends. It cannot have a limited end and another extending indefinitely. Regarding the concept of angle, not only did prospective teachers have troubles to explain angle using symbols, but also they all, except two, provided incorrect explanations. Teacher candidates mostly defined angle as the gap between rays, line segments or lines, revealing that what they were in fact thinking as angle was the degree of angle or the interior of an angle. The fact that prospective teachers perceived the degree of angle as angle may be caused by the definitions they saw in textbooks since primary school. Since it is not until high school textbooks, angles are treated as the connection of rays instead of a gap in between. It can be said that the shortcomings of students as regards the definition of angle is the result of not properly learning the concept in high school and still advancing with what they were taught back in primary and secondary schools. Furthermore, this mistake can also stem from the incorrect terminology used in the education of geometry, the scarce use of mathematical expression and symbols by prospective teachers during their past courses or their inability to feel the necessity of that language.

The study demonstrates that only nine out of the 42 prospective teachers were able to explain correctly the Pythagorean Theorem, which is a notion that students have frequently encountered in math classes since 8th grade in secondary school. A majority of those who gave an incorrect answer failed to use the mathematical term of hypotenuse when explaining the formula or mentioned irrelevant things. According to [18], there are also a series of extra-school factors having an influence on developing a propensity to use the language of mathematics, one of those being the inadequacy of the names of the mathematical terminology with their meanings or their inability to evoke them. When these expressions are memorized without their meanings being interiorized conceptually, it would become a mathematical vocabulary that students will not know why they would use it for.

Another result obtained in the study is that only eight prospective teachers were able to answer the surface area formula of a trapezoid by using oral language. When explaining this formula, most of the prospective teachers said bases should be summed, failing to notice that what should be summed in fact are not bases themselves but their length. This clearly shows that prospective teachers have not developed the concept of measure. Moreover, a different mistake was observed in the following explanation provided by prospective teachers to the surface area of a trapezoid: "It equals to the half of the sum of parallel lines, multiplied by the height". The teacher candidate who gave this explanation opted to sum the length of lines. However, it is not possible to sum lines, which have an infinite length. The teacher candidate might have mistakenly said the sum of lines when trying to describe the lengths of line segments. This may be caused by the teacher candidate's lack of attention to the concepts used. The study also showed that students orally explaining the formula used to calculate the surface area of a cone did resort to mathematical terminology, however incorrectly. Teacher candidates tried to explain the surface area of a cone describing the base of the cone as a ring, mentioning edges in a cone or including the surface of a ring to the formula. In fact, the cone consists of a circle in its base and circle sectors in its lateral surfaces while it does not have edges. Teacher candidates even referred to the calculation of the surface of a ring. However, to calculate a surface area of a shape, it needs to refer to an area and has to be in two dimensions as a surface is the value of two-dimension area within certain limits [30]. A 
ring is a single dimension geometric form, therefore does not have any surface area. This may show that the teacher candidate has not properly understood the concept of surface.

As symbolic and oral languages are two important components of the field language of mathematics, two factors are important for the development of mathematical language. Teachers should become role models to their students in using mathematical language correctly and effectively [31]. Teachers should also know about mathematics and convey knowledge in a way that students can comprehend the concepts accurately and properly [32]. One of the most important elements ensuring that students can learn mathematics is teachers' sufficiency of knowledge and their ability to convey that knowledge with an adequate language. This requires teachers to use mathematical language effectively during lessons [29]. Considering that prospective teachers, who will become the teachers of the future, will convey concepts with mathematical language, this skill needs to be introduced during the formation processes. Education and learning processes should not only focus on operational knowledge, but also the use of explanatory symbolic and oral language and prospective teachers' skills should be developed accordingly. If concepts are learned and taught adequately enough, success in mathematics will likewise increase.

As a result, in this study it was determined that the prospective teachers could not use the language of the mathematics correctly as definition and symbol. Prospective teachers were found to be very weak in questions which especially asked to explain concepts with their symbols. Findings obtained in the study are thought to be able to aid the university teacher on the lesson planning and training practice in university. It is very important the usage of correct mathematical language and exact meanings of mathematical words are used in the formation and development of mathematical ideas as correct [29]. Teachers should not only use mathematical language as correct in their lectures, but also they should warn their students in this regard and take into account usage of correct language when constructing lesson plans [29].

\section{Acknowledgements}

This study has been presented at the International Multidisciplinary Studies Congress (Imsc), Antalya, Turkey.

\section{REFERENCES}

[1] Milli Eğitim Bakanlığ1 [MEB] (2009). İlköğretim matematik dersi 6-8. sinıflar öğretim programı. Ankara: Milli Eğitim
Basımevi.

[2] Cirillo, M., Bruna, R. K., \& Herbel-Eisenmann, B. (2010). Acquisition of mathematical language: Suggestions and activities for English language learners. Multicultural Perspectives, 12 (1), 34-41.

[3] Sarama, J. \& Clements, D. H. (2009). Early childhood mathematics education research: Learning trajectories for young children. New York: Routledge.

[4] Clements, D. H. \& Sarama, J. (2014). Learning and teaching early math: The learning trajectories approach. New York: Routledge.

[5] Kranda, J. (2008). Precise mathematical language: Exploring the relationship between student vocabulary understanding and student achievement (Master's thesis). Retrieved from http://digitalcommons.unl.edu/mathmidsummative.

[6] Çalıkoğlu Bali, G. (2002). Matematik öğretiminde dil ölçeği. Hacettepe Üniversitesi Eğitim Fakültesi Dergisi, 23, 57-61.

[7] Korhonen, J., Linnanmäki, K. \& Aunio, P. (2014). "Learning difficulties, academic well-being and educational dropout: a person-centred approach". Learning and Individual Differences, 31, 1-10.

[8] Woods, G. (2009). An investigation into the relationship between the understanding and use of mathematical language and achievement in mathematics at the foundation stage. Procedia-Social and Behavioral Sciences, 1(1), 2191-2196.

[9] Orton, A. \& Frobisher, L. (2005). Insights into teaching mathematics [Elektronic]. London: Continuum.

[10] Schleppegrell, M.J. (2007). The linguistic challenges of mathematics teaching and learning: A research review. Reading \& Writing Quarterly, 23(2), 139-159.

[11] Cobb, P., Wood, T. \& Yackel, E. (1994). Discourse, mathematical thinking and classroom practice. In E. A. Forman, N. Minick \& C. Addison Stone (Eds.), Contexts for learning: Sociocultural dynamics in children's development (pp. 91-120). New York: Oxford University Press.

[12] Jamison, R. E. (2000). Learning the language of mathematics. Language and Learning across the Disciplines, $4,45-54$

[13] National Council of Teachers of Mathematics (NCTM), (1991). Professional Standards for Teaching Mathematics.

[14] Toptaş, V. (2015). Matematiksel dile genel bir bakış. International Journal of New Trends in Arts, Sports \& Science Education, 4(1), 18-22.

[15] Osterholm, M. (2006). Characterizing reading comprehension of mathematical texts. Educational Studies in Mathematics, 63(3), 325-346.

[16] Capraro, M. M., \& Joffrion, H. (2006). Algebraic equations: Can middle-school students meaningfully translate from words to mathematical symbols? Reading Psychology, 27, 147-164.

[17] Keşan, C., Kaya, D. \& Yetişir, Ş. (2008). A research on the impact of the students' success resulting from the coordination of Turkish- mathematics lessons. Bilim, Ĕgitim 
ve Düşünce Dergisi, 8(2).

[18] Yeşildere, S. (2007). İlköğretim matematik öğretmen adaylarının matematiksel alan dilini kullanma yeterlikleri, Boğaziçi Üniversitesi Ĕ̈itim Dergisi, 24(2), 61-70.

[19] Pazarbaş1, B. N. \& Es, H. (2015). İlköğretim matematik öğretmen adaylarının analitik geometri alan dilini kullanma becerileri ve tutumlarının incelenmesi, Uluslararası Ĕgitim Bilimleri Dergisi, 2 (5), 529-535.

[20] Rudd, L. C., Lambert, M. C., Satterwhite, M. \& Zaier, A. (2008). Mathematical language in early childhood settings: What really counts? Early Childhood Education Journal, 36(1), 75-80.

[21] Burns, M. (2007). About teaching mathematics A K-8 Resource. USA: Math Solutions.

[22] Gonzales, P., Williams, T., Jocelyn, L., Roey, S., Kastberg, D. \& Brenwald, S. (2009). Highlights from TIMSS 2007: Mathematics and science achievement of U.S. fourth and eighth-grade students in an international context.

[23] Kılıç, Ç. (2003). Illköğretim 5. sınıf matematik dersinde van hiele düzeylerine göre yapılan geometri öğretiminin ögrencilerin akademik başarıları, tutumları ve hatırda tutma düzeyleri üzerindeki etkisi, Yüksek Lisans Tezi, Anadolu Üniversitesi Eğitim Bilimleri Enstitüsü, Eskişehir.

[24] Doğan M. \& Güner, P. (2012). İlköğretim matematik öğretmen adaylarının matematik dilini anlama ve kullanma becerilerinin incelenmesi. X. Ulusal Fen Bilimleri ve Matematik Eğitimi Kongresi. Niğde, Turkey.
[25] National Council of Teachers of Mathematics. (2000). Principles and standards for school mathematics. Reston

[26] Miles, M. \& Huberman, M. (1994). An expanded sourcebook qualitative data analysis. Second Edition. California: Sage Publications.

[27] Argün, Z., Arıkan, A., Bulut, S., \& Halıcıoğlu, S. (2014). Temel matematik kavramlarn künyesi [Tags of Basic Mathematical Concepts]. Ankara: Gazi, Turkey.

[28] Kula-Yeşil, D. (2015). Sekizinci sınıf öğrencilerinin dörtgenler bağlamında matematik dili kullanımları: Sentaks ve semantik bileşenler (Yayımlanmamış yüksek lisans tezi). Eskişehir Anadolu Üniversitesi/Eğitim Bilimleri Enstitüsü, Eskiş̧ehir.

[29] Raiker, A. (2002). Spoken language and mathematics. Cambridge Journal of Education, 32 (1), 45-60.

[30] Lehrer, R. (2003). Developing understanding of measurement. In J. Kilpatrick, W. Gary Martin, \& D. Schifter (Eds.), A research companion to principles and standards for school mathematics (pp. 179-192). Reston, VA:The National Council of Teachers of Mathematics.

[31] Morgan, C. (2011). Communicating mathematically. In S Johnston-Wilder, P. Johnston-Wilder, D. Pimm \& C. Lee (Eds.), Learning to teach mathematics in the secondary school (pp. 146-161). London: Routledge.

[32] Philipp R., Thanheiser, E. \& Clement, L. (2002). The role of a children's mathematical thinking experience in the preparation of prospective elementary school teachers, International Journal of Educational Research, .37, 195. 